\title{
Nutritional influences on the fibrinolytic system
}

\section{By D. Ogston, Department of Medicine, Phase II Buildings, Aberdeen Royal Infirmary, Foresterhill, Aberdeen}

Knowledge relating to the influences of nutrition on fibrinolysis is fragmentary. In this account the fibrinolytic system is briefly described and the information on its relation to nutrition reviewed.

\section{Fibrinolytic system}

In addition to the mechanisms which achieve haemostasis by the formation of fibrin-stabilized platelet plugs, man possesses an efficient system designed to remove unwanted or excessive fibrin. The enzyme which cleaves fibrin into soluble degradation products is termed plasmin $(E C$ 3.4.4.14); it is present in the circulation as a zymogen known as plasminogen. The activation of plasminogen to plasmin is achieved by agents termed plasminogen activators. The major activators of blood and tissues are of two types which differ in structure and properties. They are termed urokinase-type activator and tissue-type activator: only the latter has a high affinity for fibrin. Vascular endothelial cells contain tissue-type activator and this can be released into the circulation by such stimuli as exercise, venous occlusion and vasoactive agents.

Blood also contains inhibitors of the fibrinolytic system which can neutralize the activity of either formed plasmin or plasminogen activator. The principal inhibitor of plasmin is a 70000 dalton glycoprotein termed $\alpha_{2}$-antiplasmin, and there is accumulating evidence for the existence of a specific inhibitor of plasminogen activator distinct from the known plasma protease inhibitors.

A number of hypotheses on the mechanism of fibrinolysis has been advanced over the past two decades, but it is now generally agreed that circulating plasminogen is adsorbed onto fibrin, the interaction being mediated through lysine-binding sites on the plasminogen molecule (Wiman \& Collen, 1978). Tissue-type activator is also bound to fibrin and in this situation its activating properties are markedly enhanced. It is likely that fibrinolysis takes place through the activation of fibrin-bound plasminogen by fibrin-bound activator leading to the localized formation of plasmin and the consequent degradation of the fibrin. Any free plasmin released into the plasma is rapidly inactivated by $\alpha_{2}$-antiplasmin, preventing destruction of fibrinogen and other susceptible proteins.

The importance of the physiological role of the fibrinolytic system in the prevention of fibrin deposition and persistence may be deduced from the thrombotic tendency in families with a hereditary defect in the plasminogen molecule leading to impaired plasmin activity on activation (Aoki, 1984) and, more strikingly, in the families with impaired release of plasminogen activator from the blood vessel wall (Johansson et al. 1978; Jørgensen et al. 1982; Stead et al. 1983). 
The fibrinolytic system could theoretically be influenced by nutritional factors in a number of ways. Absorbed dietary constituents could directly affect circulating components of the system, including inhibition of plasminogen activator, interference with the lysine-binding sites of plasminogen, or neutralization of fibrinolytic inhibitors. Alternatively, absorbed agents could stimulate or inhibit the release of plasminogen activator from the vascular endothelium. Additionally, nutrients may influence the synthesis of components of the fibrinolytic system.

\section{Dietary constituents implicated in the enhancement of fibrinolysis}

A number of dietary constituents have been claimed to increase plasma fibrinolytic activity; some of these are detailed in Table 1 .

Onions and garlic. The ingestion of approximately $50 \mathrm{~g}$ onions (Allium cepa), raw, fried, boiled or dried and reconstituted with water, has been reported to accelerate plasma fibrinolytic activity (Menon et al. 1968; Menon, 1970). Garlic (Allium sativum) has been found to have a similar effect (Bordia et al. 1975). The active principles of onion and garlic and the mechanism by which they influence fibrinolysis is not established, but sulphur-containing compounds have been postulated as the active agents (Bordia et al. 1975). In one study the S-containing amino acid cyclo-allicin was identified in extracts of onion and found to have fibrinolysis-enhancing properties when fed to volunteers (Augusti et al. 1975).

Capsicum. Limited studies have suggested that the ingestion of peppers might increase blood fibrinolytic activity. In one study, however, the effect was seen immediately after the meal and fibrinolysis had returned to normal $30 \mathrm{~min}$ later, indicating that any effect was unlikely to be related to the absorption of an active ingredient (Wasantapruek et al. 1974). More recently, the same group has claimed that the greater plasma fibrinolytic activity found in Thai people compared with Americans living in Thailand is the result of the frequent use of capsicum on food by the Thais (Visudhiphan et al. $\mathrm{r} 982$ ).

Caffeine. It has also been suggested that caffeine in beverages may increase plasma fibrinolytic activity. This was based on the shortening of the dilute whole-blood-clot lysis time after drinking coffee containing about $150 \mathrm{mg}$ caffeine and the abolition of this increase when decaffeinated coffee was taken (Al Samarrae \& Truswell, 1977).

Table I. Dietary constituents implicated in the enhancement and reduction of plasma fibrinolytic activity

\begin{tabular}{ll}
\multicolumn{1}{c}{ Enhancement } & \multicolumn{1}{c}{ Reduction } \\
Onion (Allium cepa) & Lipids \\
Garlic (Allium sativum) & Vitamin E \\
Caffeine & Beer \\
Capsicum & Wine \\
Ascorbic acid & Cider \\
Glucose &
\end{tabular}


Ascorbic acid. It has been claimed that plasma fibrinolytic activity is increased after a single dose of $\mathrm{I} g$ ascorbic acid (Bordia et al. 1978 ), but others have reported that a daily supplement of $I \mathrm{~g}$ over a 3 -month period did not affect fibrinolytic activity (Crawford et al. 1975).

Glucose. Information on the effect of glucose on fibrinolysis is discordant. Patients with vascular disease have been reported to show an increase in blood fibrinolytic activity after $50 \mathrm{~g}$ glucose (Tsapogas et al. I 962); in another study the increase in fibrinolysis was only seen in those with a low fasting level of fibrinolytic activity (Tanser, 1966). A high-glucose diet given for $23 \mathrm{~d}$ did not produce a significant alteration in plasma fibrinolytic activity.

\section{Dietary constituents implicated in the reduction of fibrinolysis}

Table 1 also lists some of the dietary constituents which have been reported to decrease blood fibrinolytic activity.

Lipids. Appreciation of the epidemiological association between a high-saturated-fat diet and a high incidence of ischaemic heart disease together with the development of simple assays of blood fibrinolytic activity led to many studies in the late 1950 s and the 1960 s into the effect of lipids on fibrinolysis, particularly on the influence of alimentary lipaemia on plasma fibrinolytic activity. Interest in such studies faded without any definitive conclusion being made. Inexplicably, the results of the reported studies have been contradictory. Some investigators found that a meal rich in either saturated or unsaturated fat decreased plasma fibrinolytic activity; others found that only meals of saturated fat did so, while a number reported that fibrinolytic activity was unaffected by either type of fat (Ogston, 1983).

Other studies have indicated a relation between blood lipids and fibrinolysis. For example, reduction in the serum triglyceride and cholesterol concentrations in patients with hyperlipidaemia by dietary means has been found to be associated with a rise in blood fibrinolytic activity (Elkeles et al. 1980 ).

$V i t a m i n E$. It has been shown that $\alpha$-tocopherol inhibits the activity of plasmin and plasminogen activators in vitro (Moroz \& Gilmore, 1976; Ogston \& West, $198 \mathrm{r}$ ), but the inhibitory action was found to be abolished in the presence of plasma (Ogston, 1983). The conclusion that $\alpha$-tocopherol is unlikely to influence fibrinolysis in vivo is supported by preliminary experiments showing that $\mathbf{I} \mathbf{g}$ oral doses do not cause inhibition of plasma fibrinolytic activity.

$B e e r$, wine and cider. There is now considerable evidence that certain beverages cause inhibition of blood fibrinolytic activity. In the initial study it was noted that fibrinolysis is substantially reduced for some hours after drinking beer, wine or cider whereas gin, whisky or absolute ethanol had no effect, indicating that the inhibition is not due to the alcohol content of these beverages per se (Fearnley et al. 1960). Later in vitro studies demonstrated that wine contains a heat-stable agent which can inhibit plasminogen activator: a pectin was isolated from grape pulp and proposed as the inhibitory substance (Nilsson et al. 1961). 
Chlorogenic acid<smiles>O=C(CCc1ccc(O)cc1)c1c(O)cc(O)cc1Cl</smiles>

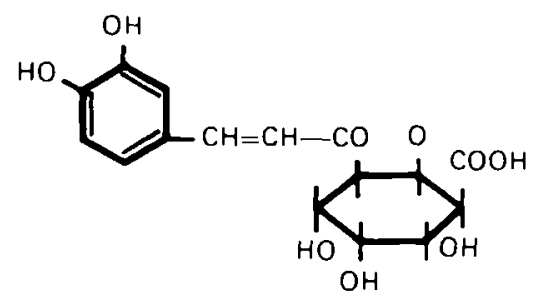<smiles>Oc1cc(O)c2c(c1)OC(c1ccc(O)c(O)c1)C(O)C2</smiles><smiles>Oc1cc(O)c2c(c1)OC(c1ccc(O)c(O)c1)C(O)[C@H]2c1ccc(O)c2c1OC(c1ccc(O)c(O)c1)[C@H](O)C2</smiles>

Fig. 1. The polyphenols of apple products.

More recently the influence of cider on plasma fibrinolytic activity has been re-examined (Anderson et al. 1983); it was confirmed that there is a marked decrease in fibrinolysis after drinking 500 or $750 \mathrm{ml}$ cider, and in vitro experiments demonstrated that diluted and neutralized cider inhibits plasmin and plasminogen activators. In further studies attempts to separate the inhibitory substances in cider by gel filtration revealed that inhibitory activity consistently co-eluted with the brown colouration which is due to the presence of phenols (Ogston et al. 1985). In addition, the inhibitory activity of cider was removed by adsorption with polyvinylpyrrolidine, a compound commonly used to remove phenolic substances from plant extracts. The polyphenols of apple products were, therefore, examined in vitro for effects on fibrinolysis. These polyphenols consist of chlorogenic acid, phloridzin, epicatechin and procyanidins in various polymeric forms (Fig. I). In a urokinase-induced clot lysis system neither chlorogenic acid nor phloridzin influenced clot lysis at a final concentration of $500 \mu \mathrm{g} / \mathrm{ml}$. At this concentration epicatechin had a slight inhibitory action while the procyanidins were markedly inhibitory, particularly the polymeric form which produced detectable inhibition at a concentration of $\mathrm{I} \mu \mathrm{g} / \mathrm{ml}$.

To localize the site of action of the polyphenols in prolonging the urokinase-induced-clot lysis time, each procyanidin form was tested for inhibition of the amidolytic activity of plasmin and urokinase. Inhibition of plasmin activity increased progressively in the order dimeric, trimeric, oligomeric and polymeric 
form, and inhibition by the polymeric form was detectable at a concentration of $0.5 \mu \mathrm{g} / \mathrm{ml}$. In contrast, the amidolytic activity of urokinase was not inhibited by any of the cider polyphenols. These experiments, however, do not establish that it is the procyanidins which are responsible for the reduction in plasma fibrinolytic activity found after drinking cider. The passage of procyanidin molecules from the intestinal tract into the circulation has yet to be demonstrated.

\section{Obesity and fibrinolytic activity}

It has been shown repeatedly that obese people have reduced blood fibrinolytic activity (Ogston \& McAndrew, 1964; Meade et al. 1979), but the explanation for this association has not emerged. The possibility that it is due to failure of synthesis or release of plasminogen activator from the vascular endothelium has been examined, but the results of such studies have been discrepant; the fibrinolytic response to venous occlusion has been reported to be normal (Grace, 1968), whereas the plasminogen activator content of vessel walls has been found to be low in overweight subjects (Almer \& Janzon, 1975). In one study the reduced plasma activator levels could not be attributed to changes in plasma triglyceride, free fatty acid, insulin or glucose (Grace \& Goldrick, I968).

Dietary restriction sufficient to induce rapid weight loss in obese subjects has been observed to be associated with an increase in plasma fibrinolytic activity, but the increase was maintained only while weight loss continued (Ogston \& McAndrew, 1964). A similar increase in fibrinolysis was also seen in adults of normal initial body build subjected to starvation and it was concluded that the rise in activity is related to the metabolic changes of starvation.

The studies outlined in this paper provide a number of hints that nutritional factors may influence the fibrinolytic system of man, and thereby play a role in the predisposition or prevention of thrombosis. Attention to this area of research has been minimal in recent years and it is likely that a number of important relations between nutrients and fibrinolysis remain to be elucidated.

\section{REFERENCES}

Almer, L.-O. \& Janzon, L. (1975). Thrombosis Research 6, 17 I-1 75.

Al Samarrae, W. \& Truswell, A. S. (1977). Atherosclerosis 26, 255-260.

Anderson, J. A., Gow, L. A. \& Ogston, D. (1983). Acta Haematologica 69, 344-348.

Aoki, N. (1984). Seminars in Thrombosis and Hemostasis 10, 42-50.

Augusti, K. T., Benaim, M. E., Dewar, H. A. \& Virden, R. (1975). Atherosclerosis 21, 409-416.

Bordia, A., Bansal, H. C., Arora, S. K. \& Singh, S. V. (1975). Atherosclerosis 21, $15^{-1} 9$.

Bordia, A., Paliwal, D. K., Tain, K. \& Kothari, L. K. (1978). Atherosclerosis 30, 35 I-354.

Crawford, G. P. M., Warlow, C. P., Bennett, B., Dawson, A. A., Douglas, A. S., Kerridge, D. F. \& Ogston, D. (1975). Atherosclerosis $21,45^{\mathrm{I}-454}$.

Elkeles, R. S., Chakrabarti, R., Vickers, M., Stirling, Y. \& Meade, T. W. (1980). British Medical Yournal 281, 973-974.

Fearnley, G. R., Ferguson, J., Chakrabarti, R. \& Vincent, C. T. (1960). Lancet i, 184-186.

Grace, C. S. (1968). Clinical Science 34, 497-504.

Grace, C. S. \& Goldrick, R. B. (1968). Fournal of Atherosclerosis Research 8, 705-719.

Johansson, L., Hedner, U. \& Nilsson, I. M. (1978). Acta Medica Scandinavica 203, 477-480. 
Jørgensen, M., Mortensen, J. Z., Madsen, A. G., Thorsen, S. \& Jacobsen, B. (1982). Scandinavian Journal of Haematology 29, $217^{-223}$.

Meade, T. W., Chakrabarti, R., Haines, A. P., North, W. R. S. \& Stirling, Y. (1979). British Medical Yournal i, 153-156.

Menon, I. S. (1970). British Medical fournal ii, $42 \mathrm{I}$.

Menon, I. S., Kendel, R. Y., Dewar, H. A. \& Newell, D. J. (1968). British Medical fournal 3, $35^{1-35^{2}}$.

Moroz, L. A. \& Gilmore N. J. (1976). Nature 259, 235-237.

Nilsson, I. M., Björkman, S. E., von Studnitz, W. \& Hallen, A. (196r). Thrombosis et Diathesis Haemorrhagica 6, $177-187$.

Ogston, D. (1983). The Physiology of Hemostasis London: Croom Helm.

Ogston, D., Lea, A. G. H., Langhorne, P. \& Wilson, S. B. (1985). British Fournal of Haematology (In the Press).

Ogston, D. \& McAndrew, G. M. (1964). Lancet i, 1205-1207.

Ogston, D. \& West, L. L. (1981). Fournal of Physiology 316, i P.

Stead, N. W., Bauer, K. A., Kinney, T. R., Lewis, J. G., Campbell, E. E., Shifman, M. A., Rosenberg, R. D. \& Pizzo, S. V. (1983). American fournal of Medicine 74, 33-39.

Tanser, A. R. (1966). Lancet ii, 147.

Tsapogas, M. J., Cotton, L. T., Flute, P. T. \& Murray, J. G. (1962). Lancet i, 121 3-1215.

Visudhiphan, S., Poolsuppasit, S., Piboonnukarintr, O. \& Tumliang, S. (1982). American fournal of Clinical Nutrition 35, $145^{2-1} 45^{8}$.

Wasantapruek, S., Poolsuppasit, S. \& Piboonnukarintr, O. (1974). New England Yournal of Medicine 290, $1259-1260$.

Wiman, B. \& Collen, D. (1978). Nature 272, 549-550. 